\title{
Microcephaly, characteristic facies, joint abnormalities, and deficient leucocyte chemotaxis: a further case of the syndrome of Say et al
}

Claudia Perandones, Roxana I Cerretini, Ramón M Vargas Vera, Eliseo I Aranda, Liliana G Alba, Omar H Pivetta

\begin{abstract}
We report on a 13 year old boy with microcephaly, sloping forehead, prominent nose, scoliosis, and flexion contractures involving the elbows and knees. The patient showed severe mental and growth retardation. Since birth and up to the present he has suffered from multiple and varied infections. Immunological studies showed a marked decrease in leucocyte chemotaxis. Clinical and laboratory findings confirm the similarity of this case to the two brothers described by Say et al. We have not found any descriptions of similar patients.
\end{abstract}

The purpose of this paper is to contribute to the phenotypic delineation of this syndrome and to highlight the need for immunological investigation in patients with multiple congenital malformations.

( $\mathcal{F}$ Med Genet 1996;33:227-229)

Key words: microcephaly; short stature; developmental delay; chemotactic defect.

In 1986, Say et al described, in this Journal, two brothers with microcephaly, short stature, developmental delay, and reduced neutrophil chemotaxis.

The present case, together with those previously reported, leads to the assumption that the association of physical malformations and immunological abnormalities found in these patients is not fortuitous but that it reflects a genetic syndrome.

\section{Case report}

The proband was the product of a preterm pregnancy of a healthy, non-consanguineous couple. At the time of birth the mother was 21 and the father was 26 years of age. He has a healthy 12 year old sister. There was no relevant family history. The pregnancy was uneventful and there was no exposure to teratogens. Vaginal delivery was at 30 weeks with a birth weight of $1600 \mathrm{~g}$. The neonatal period was uneventful except for the development of umbilical infection. By the end of the first month of life microcephaly was noted; a CT scan reported cerebral atrophy and microcephaly.

The patient later developed bacterial pneumonia with two admissions to hospital because of pleural effusion, haemorrhagic varicella, enteritis, hepatitis, and recurrent otitis, on one occasion associated with cellulitis of the ear lobe, which was surgically removed.

Physical examination at the age of 13 showed microcephaly (head circumference $-6 \mathrm{DS}$ ), weight and height below the 3rd centile, sloping forehead, and ridged metopic suture. Clinical suspicion of metopic suture synostosis was confirmed radiographically. He had abnormal hair implantation, a small face, sparse eyebrows, ocular hypertelorism, upward slanting palpebral fissures, flattened periorbital margins, prominent nasal bridge, high arched palate with irregular dental implantation, multiple caries, and micrognathia. The ears were low set and posteriorly rotated (fig 1). There was a marked reduction of subcutaneous fat.

The genitalia showed cryptorchidism and small penis. Flexion contractures in the upper extremities mainly involved the elbows, resulting in significantly limited pronation. Ulnar deviation of the second, third, and fourth fingers with clinodactyly of the fifth fingers on

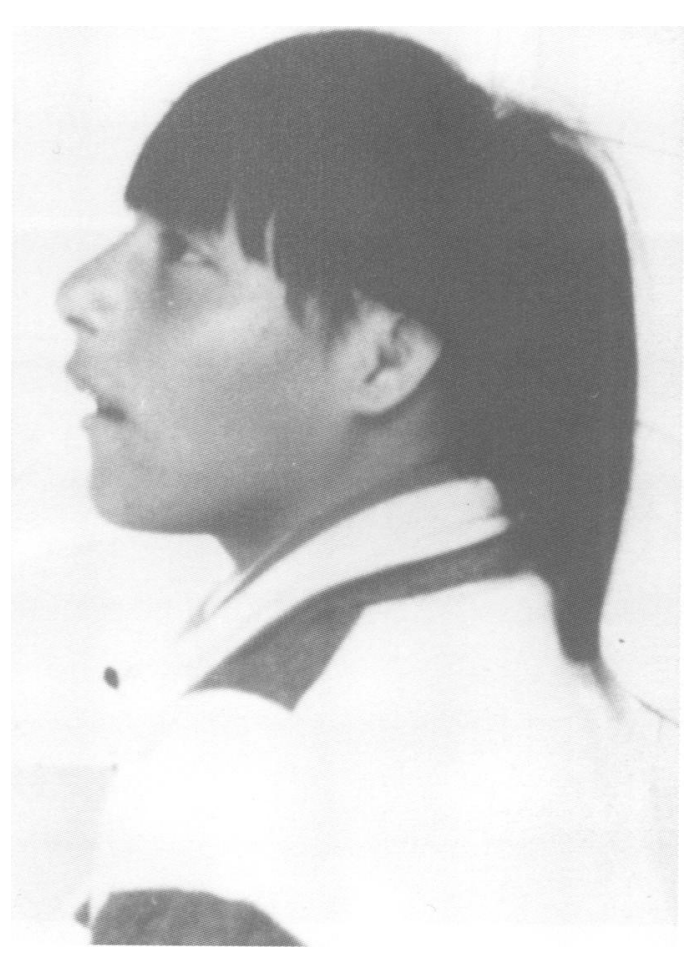

Figure 1 The proband at 13 years of age. Note severe microcephaly. 


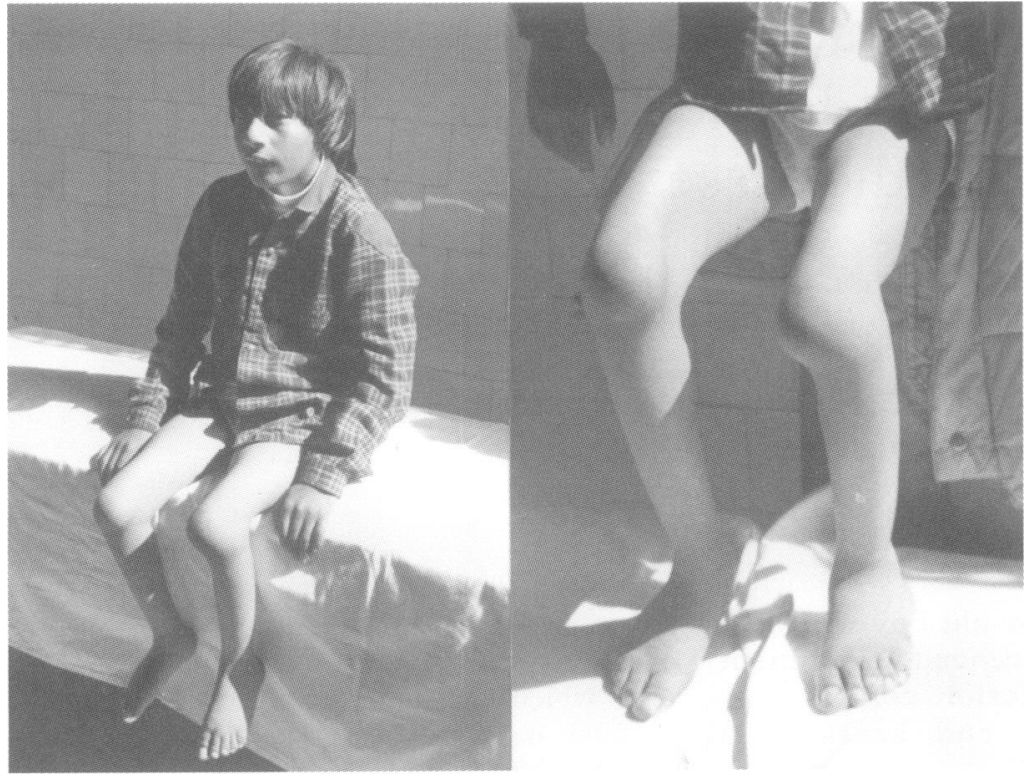

Figure 2 Note remarkable swelling of knees and lymphoedema over the dorsum of the feet.
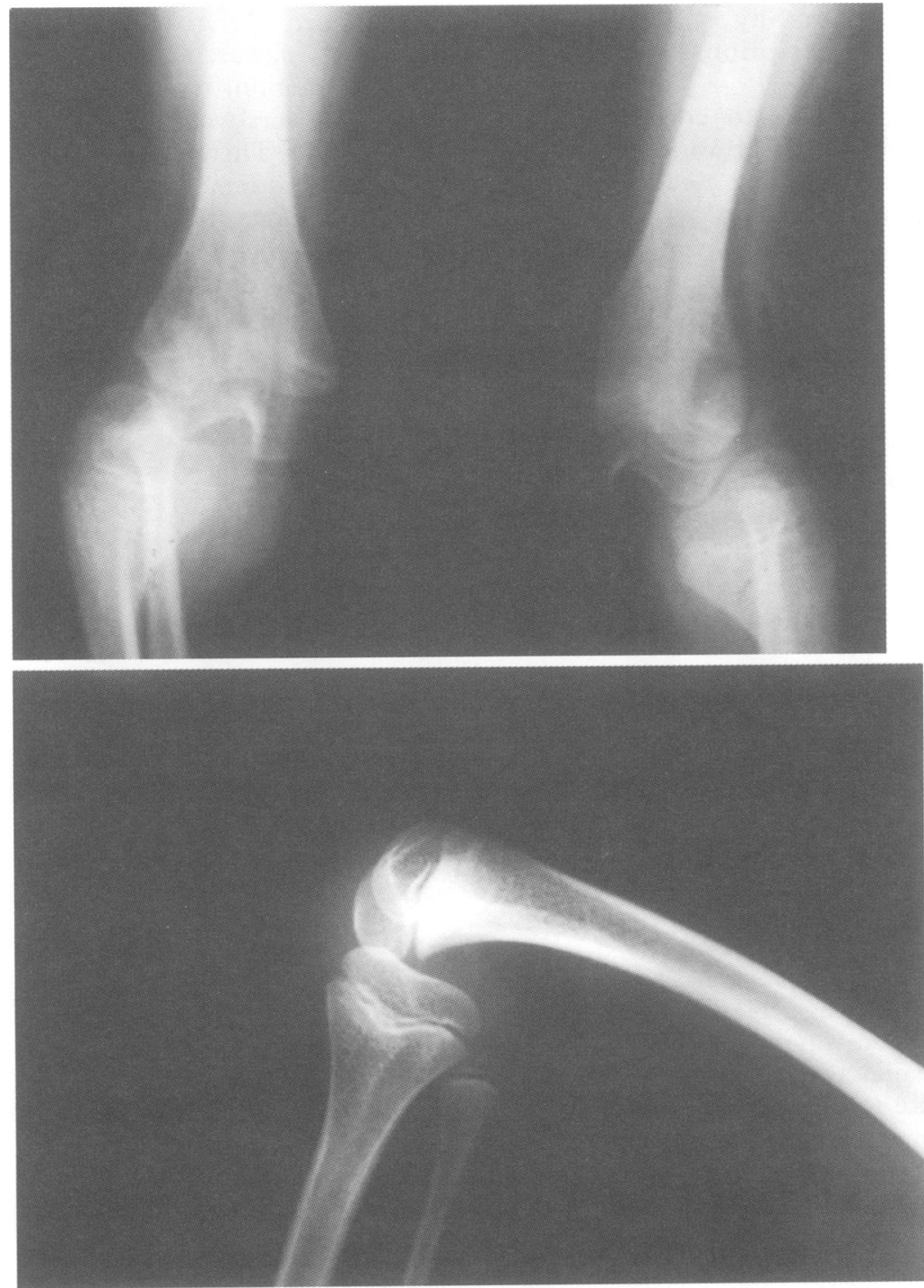

Figure 3 Radiographs of both knees. (Top) Anteroposterior view of both knees showing severe bilateral luxation and posterolateral displacement of the patella. (Bottom) Lateral view of the patient's right knee.
Table 1 Neutrophil chemotactic assay*

\begin{tabular}{lcll}
\hline Reagent & $\begin{array}{l}\text { Normal donor } \\
\text { (cells/field) }\end{array}$ & $\begin{array}{l}\text { Patient } \\
\text { (cells/field) }\end{array}$ & $\begin{array}{l}\text { One tail } \\
\text { statistical } \\
\text { significance }\end{array}$ \\
\hline $\begin{array}{l}\text { FMLP 10-7 M } \\
\begin{array}{l}\text { Activated } \\
\text { serum }\end{array}\end{array}$ & $\begin{array}{c}80 \text { (SEM 6) } \\
126 \text { (SEM 14) }\end{array}$ & $\begin{array}{l}41 \text { (SEM 3) (SEM 9) } \\
\text { 86 }\end{array}$ & $\begin{array}{l}\mathrm{p}<0.01 \\
\mathrm{p}<0.05\end{array}$ \\
\hline
\end{tabular}

* Chemotaxis to FMLP 10-7 $\mathrm{M}$ and to activated human serum by ZYMOSAN (as a C5 source) diluted $1 / 20$ was determined. Results are expressed as the $\bar{x}$ mean number of cells migrating per microscopic field $(400 \times)$ as a chemotactic response after subtracting the negative control (migration in absence of the attractant).

Table 2 Clinical features*

\begin{tabular}{lll}
\hline Case 1 & Case 2 & $\begin{array}{l}\text { Our } \\
\text { patient }\end{array}$ \\
\hline
\end{tabular}

$\begin{aligned} & \text { General } \\ & \text { Postnatal growth retardation }+\end{aligned}++$

CNS

$\begin{array}{llll}\text { Developmental delay } & + & + & + \\ \text { Flexion contractures } & + & + & +\end{array}$

Flexion

Cranium
Microcephaly

Craniosynostosis

Sloping forehead

Ears

Large, protruding

Nose

Beaked, prominent

High nasal bridge

Mouth

Carp shaped

High arched palate

Micrognathia

Anus

Stenosis

Extremities

Dislocated hips

Hypoplastic patellae

Spine

Scoliosis

Genitalia

Small penis

Small testes

Skin

Eczematous lesions

Decreased subcutaneous fat +

$\begin{array}{lll}+ & + \\ + & + \\ + & +\end{array}$

* Findings in the present patient as compared to those reported by Say et al. ${ }^{1}$

both hands and deep creases on the palms completed the picture in the upper limbs. The lower extremities showed flexion, swelling of the knees, and lymphoedema over the dorsum of the feet (fig 2). Radiological studies showed bilateral luxation of the knees with posterolateral displacement of the patellae (fig 3). The skin was dry with eczematous patches and excoriated lesions.

There was a history of delayed development. At present the patient shows severe mental impairment together with a serious language deficit, despite adequate hearing. He has never walked.

\section{Laboratory studies}

IMMUNOLOGICAL STUDIES

Neutrophil chemotactic assay was performed. Cell migration was quantified using a 48 well microchemotaxis chamber (Neuroprobe, Cabin John, MD) and $10 \mu \mathrm{m}$ thick, $3 \mu \mathrm{m}$ pore 
diameter PVP free polycarbonate filters (Nucleopore, Bethesda, MD). Attractants were diluted in PBS containing $0.1 \%$ BSA at indicated concentrations. After incubation for 30 minutes at $37^{\circ} \mathrm{C}$ in $95 \%$ humidified air and $5 \% \mathrm{CO}_{2}$, filters were removed and cells on the upper surface of the filters were scraped off with a rubber policeman. The filters were then fixed, stained with Diff-Quick (Dade Diagnostics Inc, Aguada, PR), and mounted on a microscope slide. Neutrophil migration was scored by counting the number of cells that reached the lower surface of the filter in five high power $(400 \times)$ microscopic fields $(\mathrm{HPF})$ per well. ${ }^{2}$ The results are expressed as mean (SEM) of mean triplicate values obtained from a normal donor and the patient.

Leucocyte chemotaxis values were significantly lower in the patient than in the control, as shown in table 1 .

Serum protein electrophoresis was within normal limits.

\section{CYTOGENETIC STUDY}

One hundred metaphases were analysed in cultured peripheral blood lymphocytes using standard banding techniques at a 400 band level. All metaphases showed a 46,XY karyotype. ${ }^{34}$

\section{Discussion}

The coexistence of multiple congenital abnormalities and immunodeficiency is puzzling. Multiple entities with deficiencies in chemotaxis have been described; however, no report describes the syndrome observed by Say et $a l^{5}$ in two sibs and later by us in this case. ${ }^{5}$

The interpretation of leucocyte function in vitro must take into account the clinical status of the individual patient, as it is important to define whether abnormal function results in increased susceptibility to infection, or whether it is secondary to other aspects of the patient's condition. The onset of clinical symptoms shortly after birth, the recurrent bacterial infections, and the absence of chemotactic inhibitors in the serum strongly suggest that the chemotactic abnormality is primary. ${ }^{6}$

Clinical findings (table 2) and further complementary studies in our patient lead us to confirm that we are dealing with the entity previously described by Say et $a l^{1}$ in two sibs.

The genetic basis of this syndrome is not clear at present; however, all three affected patients are male, suggesting the possibility of X linkage. López Osuna et al described defective neutrophil chemotaxis in patients with Turner's syndrome and suggested that a gene on the $\mathrm{X}$ chromosome might be implicated in this process. The gene would have to escape inactivation in the female and be represented on the Y. Their observations have not been confirmed, nor has an isolated $\mathrm{X}$ linked chemotactic defect been described. A submicroscopic deletion of the $\mathrm{X}$ remains an intriguing possibility in these patients, but other genetic mechanisms, such as autosomal recessive inheritance or a submicroscopic autosomal rearrangement, cannot be excluded.

We are grateful for secretarial assistance provided by Susana Silva and Pablo Martini. We acknowledge Fernando Dyzenchauz for helpful suggestions.

1 Say B, Barber N, Miller GC, Grogg SE. Microcephaly, short stature, and developmental delay associated with 23:355-9.

2 Trevani AS, Fontán PA, Andonegui GA, Isturiz MA, Geffner JR. Neutrophil chemotaxis induced by immune complexes. Clin Immunol Immunopathol 1995;74:107-11

3 Barch MJ, Lawce HJ, Arsham MS. Peripheral blood culture. In: Barch MJ, ed. The ACT cytogenetics laboratory manual. 2nd ed. New York: Raven Press, 1991:17-30.

4 Seabright $M$. A rapid banding technique for human chromosomes. Lancet 1971;ii:971-2.

5 Say B, Barber N, Miller GC, Grogg SE. Association of birth defects and immunodeficiency. F Pediatr 1979;94:849-50.

6 Bowen TJ, Ochs HD, Altman LC, et al. Severe recurrent bacterial infections associated with defective adherence and chemotaxis in two patients with neutrophils deficient in chemotaxis in two patients with neutrophils deficient in

7 López Osuna M, Vega Avila E, Salamanca F, Kretschmer R Defective polymorphonuclear chemotaxis in patients with Turner's syndrome. Clin Genet 1988;34:165-71. 